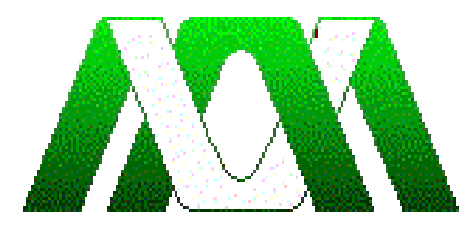

Casa abierta al tiempo

UNIVERSIDAD AUTÓNOMA METROPOLITANA

UNIDAD IZTAPALAPA

DIVISIÓN DE CIENCIAS SOCIALES Y HUMANIDADES

POSGRADO EN CIENCIAS ANTROPOLÓGICAS

La influencia del Movimiento Urbano Popular a los Movimientos Sociales Urbanos en la Ciudad de México: Un análisis de los liderazgos y los militantes de esta transición

Kitzia Mayela González González

\author{
ENSAYO \\ Para obtener el Diploma de Especialización \\ en Antropología Política
}

Director: Dr. Héctor Tejera Gaona 


\section{La influencia del Movimiento Urbano Popular a los Movimientos Sociales Urbanos en la Ciudad de México: Un análisis de los liderazgos y los militantes de esta transición}

El Movimiento Urbano Popular (MUP), ha tenido una larga trayectoria desde la década de 1920, en este proceso de surgimiento, maduración, agotamiento y transición, ha existido también una transformación en su estructura de poder y su participación política, ya que se ha ido adaptado a momentos coyunturales políticos, sociales y económicos, acontecidos en el país, y específicamente en la Ciudad de México. No obstante el MUP, ha influenciado a otro tipo de participación política, estos son los movimientos sociales urbanos, acontecidos en la Ciudad de México, ya que han retomado prácticas políticas consolidadas y perfeccionadas por el MUP.

El presente ensayo pretende hacer una relación de la participación política, de los líderes y los militantes o apoyos del Movimiento Urbano Popular (MUP), respecto a los Movimientos Sociales Urbanos (MOSU) en la actualidad, en la Ciudad de México, así como dar cuenta de esta transición; lo anterior con el propósito de identificar las posibles influencias, que el MUP ha dejado en los MOSU en su participación política en temas de vivienda y urbanismo.

En primer lugar, retomare brevemente el tipo de participación política que el MUP tuvo en la Ciudad de México. Así también, se considerara el tránsito y los cambios que el MUP tuvo respecto a sus características como movimiento social y político, en relación al movimiento social urbano; en este tránsito se consideraran aspectos partidistas, reformas políticas, cooptación de líderes, la inclusión de liderazgos a partidos políticos, el clientelismo y el papel del Estado. Además, se retomara el tipo de configuración política que se ha ido desarrollando a partir de este tránsito, se analizaran aspectos como la participación ciudadana, la sociedad civil, los movimientos sociales urbanos, los tipos de liderazgos y la gestión de la vivienda urbana. Se hará una reflexión antropológica, respecto a la influencia que está presente en este tránsito político, y que se concentra principalmente en la experiencia adquirida, en las instituciones sociales, en la comunidad, en la configuración de culturas locales, la memoria histórica y colectiva etc. En estos apartados se incluirán algunas propuestas teóricas referentes a los movimientos sociales que han a acompañado y configurado el tipo de participación política del MUP y su tránsito al MOSU. 
El Movimiento Urbano Popular (MUP) en la Ciudad de México, es producto de procesos políticos, históricos, económicos y sociales acontecidos en el país e incluso en otros países. Por una parte, estos acontecimientos tienen que ver con un proceso de migración a la Ciudad a partir de la década de 1950, durante la época de gran industrialización en el país, la cual trajo consigo, personas de todas partes de la República Mexicana que vinieron a probar suerte en la ciudad capital, estas personas traían con ellas creencias, hábitos y prácticas, propias de las zonas rurales de las que provenían; esta confluencia de factores, les permitió subsistir y adaptarse a las nuevas condiciones en la urbe, cargada de otro tipo de repertorios socioculturales y de prácticas distintas a las de provincia, y son las que, aún modificadas por el proceso de urbanización y globalización, siguen estando presentes en la participación política. Por otra parte, los procesos están ligados a las ideologías políticas y sus prácticas, presentes en América Latina, Estados Unidos y Europa; por una parte respecto a la participación política motivada por la revolución, para cambiar la realidad de gobiernos autoritarios en el mundo; y por otra, en relación a las Guerras Mundiales y crisis económicas.

El MUP tiene sus inicios desde la década de 1920, cuando comienzan a crearse los movimientos inquilinarios y las sociedades cooperativas de vivienda, integradas por trabajadores; sin embargo, como menciona Juan Ramírez Sáiz, no es sino hasta la década de 1940 y a partir de ese momento, que el MUP comienza a repuntar, debido a la reconfiguración urbana de la Ciudad de México, es decir, así como menciona la antropóloga Icazurriaga, "Para 1980 la superficie total del área urbana metropolitana llegó a ser de 1114.97 kilómetros cuadrados, esto es, 71.5\% más respecto a la de 1970. Para 1980, la zona metropolitana de la ciudad de México estaba integrada por el Distrito Federal con sus 16 delegaciones..." (Icazuriaga, 1992: 30).

Lo anterior trajo cambios tanto en su traza urbana, como en el tipo de vivienda, que hasta entonces, reproducía en gran medida, las creencias, hábitos y prácticas de las zonas rurales de las que provenían los migrantes, es decir, espacios en el que confluían varias familias, a las que Larissa Lomnitz denomina familias extensas, es decir, "grupos sociales compuestos de dos o más familias nucleares emparentadas entre ellas, a las que pueden agregarse otros individuos. Estos "arrimados" pueden existir también en las unidades residenciales compuestas por una sola familia nuclear" (Lomnitz, 1975: 104). Estas familias se apoyaban entre sí para salir a delante en medio de la urbe que los confrontaba con otra realidad fuera de estas unidades domésticas, ya que estas son, 
... grupo social integrado por todas las personas que viven en una misma residencia y cuyo acceso a la vivienda es a través de una entrada común. Esta definición es significativa en el contexto rural, donde hay suficiente espacio para que las familias pertenecientes a cada unidad doméstica se agrupen en un solar o casa común. En cambio, en la barriada suburbana, donde el terreno es escaso y caro, este mismo grupo doméstico podrá habitar en cuartos contiguos o vecinos, con entradas independientes, y sus integrantes podrán llevar vidas económicas separadas, a pesar de que el espacio total que ocupan en la barriada sea menor que el que ocupaban en el campo (Lomnitz, 1975: 106).

Así pues, estas unidades domésticas se formaron como vecindades, en las que se reproducían hábitos y costumbres propias de las zonas rurales, y se siguieron reproduciendo, pues les permitía sobrevivir en la ciudad. No obstante este tipo de habitar cambió en lo sucesivo, debido a que se encarecieron las viviendas en malas condiciones y tuvieron que buscar otro tipo de vivienda. Así pues como menciona Ramírez Sáiz,

La colonia "popular o proletaria" sustituye a la vecindad como forma básica de habitación para las mayorías. Estas colonias tenían una ubicación periférica. Desde el punto de vista de las luchas sociales, el inquilino pasa a segundo plano y los colonos se convierten en el nuevo agente social y en el eje de las mismas. La creación de las colonias es promovida por líderes del partido oficial (y a partir de 1944 por los integrantes del sector popular de la CNOP) a cambio de apoyo político y relaciones de clientelismo y supeditación al sistema (Ramírez, 1986: 40).

La Confederación Nacional de Organizaciones Populares (CNOP), que fue el sector popular del Partido Revolucionario Institucional (PRI), fundado en 1943, incorporó a las colonias en organizaciones semicorporativas zonales, de tal forma que como menciona M. Basolls y A. Delgado citado por Ramírez,

En 1944 existían ya ciento cincuenta colonias proletarias en el DF afiliadas a la CNOP. La Federación de Colonias Proletarias del DF se crea en abril de 1951, pero ya a mediados de los años treinta existían la Confederación de Organizaciones de Colonos del DF, la Unión Central de Colonos del DF y el Bloque Revolucionario de las Colonias del DF (Ramírez, 1986: 40).

Posteriormente, el movimiento estudiantil de 1968 y las comunidades eclesiales de base (CEB`s), fueron participes de un momento histórico clave, del cual parten la gran mayoría de liderazgos al frente del MUP. El politólogo Paul Haber, menciona que tras el movimiento estudiantil, socavado por la represión del entonces Secretario de Gobernación Luis Echeverría, se produjeron tres tendencias políticas del movimiento, una es un movimiento revolucionario; otra comprometida en tareas de construcción partidaria y participación electoral después de las reformas políticas de 1977; y por último la tendencia que tenía un deber moral con los pobres "Guiada por el concepto de "volver al pueblo", esta última tendencia se dio a la tarea de construir nuevas formas de poder social a través del trabajo de base" (Haber, 2008: 4). El MUP, proviene de esta última tendencia, motivados ante las problemáticas de vivienda, servicios públicos y trabajo. 
Este movimiento y los tipos de liderazgos surgidos entonces, conformaron los movimientos independientes de inquilinos, en colonias que surgieron al margen de la tutela del Partido Revolucionario Institucional, ubicados principalmente en zonas periféricas y municipios adyacentes al Distrito Federal (DF) (Ramírez, 1986: 40). Frente a esta situación, y en un principio, el Estado se muestra aparentemente tolerante, ya que las agrupaciones independientes tenían un carácter local y aislado, no obstante esta situación perduro hasta mediados de la década de 1970, ya que,

...se llevan a cabo las primeras experiencias sectoriales de frentes locales (Bloque Urbano de Colonias Populares [BUCP], Frente Popular Independiente [FPI], etcétera). Por su parte, la CNOP acusa una pérdida relativa de influencia entre los colonos (Ramírez, 1986: 40).

A partir de la segunda mitad de la década de 1970, hubo un cambio de perspectiva por parte del Estado, frente a estas movilizaciones independientes, que empiezan a tener una presencia política importante. Entre estos cambios, se manifiesta la represión, y el control, además de que se presentaron medidas implementadas a través de la nueva legislación y planificación urbanas. Así en medio de esta ofensiva por parte del Estado,

Aparece así en diferentes partes de la ciudad un nuevo actor social: los solicitantes de tierra y vivienda. Y se intenta mantener las bases y espacios logrados en el periodo anterior. Las luchas sobresalientes de esta etapa son: 1] el proyecto (fallido) de vincular a nivel nacional a los colonos, inquilinos y solicitantes independientes como parte del Frente Nacional de Acción Popular (FNAP), y 2] las divisiones internas que aparecen en los frentes sectoriales (BUCP y FPI) y en algunos grupos de inquilinos (Martín Carrera, etcétera) motivadas por diferencias en las concepciones orgánicas y políticas de la lucha popular (Ramírez, 1986: 41).

A finales de la década de 1970, hay una reconfiguración del MUP, este es el momento en que este movimiento se fortalece, y se caracteriza por tener presencia en la Zona Metropolitana de la Ciudad de México (ZMCM), lo que permite la alianza de distintas demandas y organizaciones, en movilizaciones conjuntas, reuniendo fuerzas para las peticiones y negociaciones ante el entonces Gobierno del Distrito Federal y el Estado de México, es en este sentido que el MUP se caracteriza en ese entonces por,

...a] el acercamiento progresivo entre colonos, inquilinos y solicitantes; b] el mayor nivel orgánico y de politización; c] la solidaridad sectorial para lograr la cobertura mutua frente al Estado; y d] la coordinación local y regional de los movimientos en el AMCM, su integración en la Coordinadora Nacional del Movimiento Urbano Popular (CONAMUP) y, en el caso de ésta, la creación de la Regional del Valle de México. Esta última está compuesta por cuatro zonales: a] Norte: las colonias y movimientos de Naucalpan y Ecatepec; b] Sur: Tlalpan, Álvaro Obregón, Contreras y Cuajimalpa; c] Oriente: Iztapalapa y Netzahualcóyotl; y d] Poniente: Centro, Azcapotzalco, Cuauhtémoc (Ramírez, 1986: 41).

A partir de los primeros años de la década de 1980, la Coordinadora Nacional del Movimiento Urbano Popular (CONAMUP) y su regional del Valle de México, tienen fuerza de movilización, 
y se han aliado con otros grupos como campesinos, obreros, maestros, estudiantes, además se crean alianzas con el "Frente Nacional en Defensa del Salario y Contra la Austeridad y la Carestía (FNDSCAC) y con la Asamblea Nacional Obrero, Campesina y Popular (ANOCP)" (Ramírez, 1986: 42). No obstante,

A partir de 1984, se acusa una doble situación: a] debilitamiento y estancamiento relativos en la estructura general y b] avances puntuales en algunas colonias y movimientos nuevos así como impulso a sectores específicos dentro de la estructura regional y de las organizaciones que la integran, es decir, de las mujeres, inquilinos y jóvenes. (...) Las reivindicaciones siguen efectuándose, principalmente en las delegaciones centrales y en las periféricas, así como en los municipios conurbados del estado de México. Los niveles de politización se elevan y, en parte, también la capacidad de negociación con el Estado, si bien éste, en el periodo, evita el reconocimiento y la relación con la regional del MUP en el Valle de México (Ramírez, 1986: 42).

En algunas colonias de las periferias de la Ciudad, se demuestran estos avances, en la formulación de planes urbanos y créditos del Fondo Nacional de Habitaciones Populares (FONHAPO) (Ramírez, 1986: 42). Así pues, las demandas del MUP son muy específicas, se centran en la vivienda y en los servicios públicos, dos necesidades apremiantes para los colonos, ya que existen otro tipo de demandas que se consideran más generales, y tienen que ver con demandas sociales y ecológicas, que son demandas que no prefiguraban en sus repertorio de necesidades inmediatas y urgentes para ellos, así pues como menciona Ramírez,

...manteniendo la caracterización general de este movimiento, es preciso distinguir varias modalidades en su seno de acuerdo con la causa que origina las luchas: a] la defensa del espacio ocupado; b] la oposición al capital inmobiliario; c] la demanda de vivienda o de apoyo para su construcción; d] el aumento y mejora de servicios urbanos; e] el rechazo a la elevación de impuestos o tarifas de servicios públicos; f] la preservación o mejora del entorno ecológico; g] la oposición a las políticas urbanas; y h] los desastres urbanos insatisfactoriamente atendidos (Ramírez, 1986: 43).

Durante los sexenios de José López Portillo (1976-82) y Miguel de la Madrid (1982-88), se intentó frenar los movimientos, deshacer organizaciones y cooptar a sus dirigentes, es decir, "el Estado levanta múltiples trabas para impedir su surgimiento y que operen como mediadores e interlocutores ante el Estado y sus aparatos" (Ramírez, 1986: 51). Así pues, como menciona Paul Haber, aunque el MUP se volvió un movimiento significativo a finales de la década de 1970, y conoció su auge a finales de la década de los ochenta, también a partir de ese momento, empezó a declinar el movimiento, cuando el proceso del liberalismo social en México, se hizo evidente a partir de 1988. A finales de 1980, algunos de los más importantes líderes del MUP y sus organizaciones, consideraron otra forma organizativa, la de los partidos políticos, no obstante, algunos no estaban de acuerdo con esta medida ya que pensaban que la transición del movimiento a los partidos políticos y el acceso a los cargos de elección popular, los alejarían de 
sus compromisos con los pobres, ya que se inclinarían a buscar el enriquecimiento y el prestigio (Haber, 2008: 2). De esta forma,

A medida que se abrieron nuevos espacios para construir partidos políticos, presentar candidaturas a cargos de elección popular y tomar las riendas del gobierno, gran parte del liderazgo del Movimiento Urbano Popular se convenció - si no lo estaba ya - de que su futuro político residía en los partidos, a lo que contribuyó de manera decisiva la elección presidencial de 1988. (...) A medida que se abrieron nuevos espacios, los líderes del CDP y la AB llegaron a la conclusión de que ahí era donde residía el futuro del poder político y de que la nueva política económica incluía oportunidades para adquirir poder individualmente y llevar sus demandas de justicia social a los salones de gobierno - ya no luchando por servicios y otras concesiones, sino tomando parte en la determinación de políticas públicas que beneficiaran a los pobres (Haber, 2008: 2).

En este tenor, en la Asamblea de Barrios (AB), que viene del movimiento estudiantil del 1968, y que surgió como una organización interna de la Coordinadora Única de Damnificados CUD, surgida a partir del sismo del 16 de septiembre de 1985, que tuvo consecuencias devastadoras para la Ciudad de México,

...argumentaban que la estructura de oportunidades políticas se encontraba madura para movilizar una fuerza mucho más allá de lo que los líderes moderados de la cud podían imaginar. (...) La Asamblea de Barrios se formó unos meses antes de que Cuauhtémoc Cárdenas iniciara su intentona presidencial de 1987-1988 (Haber, 2008: 9).

La AB tenía vínculos con la Asociación Cívica Nacional Revolucionaria (ACNR) y con Punto Crítico, esta relación fue fundamental para la formación política de los dirigentes de la $\mathrm{AB}$, que además apoyaron a Cuauhtémoc Cárdenas, candidato a la presidencia por el Partido Mexicano Socialista (PMS).

Su lectura de la estructura de oportunidad política los condujo a pensar que una transición democrática era posible ahora que Cárdenas tenía la capacidad de conducir el proceso. A pesar de los orígenes priístas de Cárdenas y de otros líderes del PRD, la dirigencia de la $\mathrm{AB}$ consideró que había llegado el momento de terminar con las prácticas de negociación y "cierre de acuerdos" con el Estado, típicas de muchos movimientos populares mexicanos (Haber, 2008: 9).

Así pues, para poder lanzar reformas estructurales de mayor impacto, la AB participó en la contienda electoral de 1988, con su candidato a la presidencia, el Superbarrio Gómez, que tenía propuestas que iban más allá de las demandas de vivienda, ya que también incluía la ecología, la deuda externa, las relaciones de dependencia con Estados Unidos y las relaciones que el PRI mantenía con el Estado. No obstante,

En diciembre de 1987 comenzaron las negociaciones formales entre el grupo de Cárdenas y los otros grupos de izquierda que presentaban candidatos presidenciales. Cuando Porfirio Muñoz Ledo se aproximó a la AB y ofreció registrar como candidatos a sus dirigentes bajo la bandera del FDN, éstos aceptaron (Cuéllar Vázquez, 1993). (...) Aunque los integrantes de la AB habían participado como miembros individuales de la cud en el convenio de concertación para la reconstrucción del terremoto, siguieron siendo implacables en su crítica hacia aquellas organizaciones que dejaron el bando de Cárdenas y se unieron a Salinas a través de la 
participación en el Pronasol. No obstante que su crítica era general, una gran parte se centraba en organizaciones específicas del movimiento popular, particularmente en el Frente Popular Tierra y Libertad, de Monterrey, y en el CDP, de Durango. Estas organizaciones se convirtieron en el centro de sus críticas por su temprana participación en el Pronasol a través de la firma fuertemente publicitada de convenios y el consiguiente papel dirigente que asumieron en la formación del Partido de Trabajo, comúnmente conocido por los líderes de la AB como el "Partido de Salinas" o "Partido del Pronasol" (Haber, 2008: 12).

La experiencia en la actividad política de los líderes del MUP, fue pieza clave para su traslado a la política de partidos, éstos se pensaban, lo suficientemente capaces de hacerle frente al partido hegemónico PRI. Sin embargo, esta decisión tuvo consecuencias para el movimiento ya que resulto en la pérdida de su vitalidad y fuerza. En la opinión de Haber, los liderazgos que se quedaron al frente de los movimientos, mientras que los liderazgos fuertes estaban en esta transición, no contaban con una estrategia efectiva para salvaguardar el MUP.

El argumento en este aspecto es que la innovación fue contenida y el declive se produjo como resultado de la forma en que se manejó la transición. La decisión de entrar a la política de partido, que inició el colapso del movimiento, no fue tomada democráticamente al interior del propio movimiento, sino que se hizo unilateralmente por el liderazgo principal del mismo. (...) Lo que era crucial, y no se hizo, era entregar las riendas del poder a un nuevo liderazgo. Desde mi punto de vista, la estrategia más prometedora habría sido que los líderes de la "generación del 68" entregaran el poder a una nueva generación de dirigentes (mayormente joven) del movimiento y mantuvieran lazos ocasionales con ellos (como asesores informales), a medida que asumían sus nuevas responsabilidades como actores estatales, para utilizar su experiencia en el movimiento. Esto no se produjo, y el poderoso Movimiento Urbano Popular se desvaneció (Haber, 2008: 3).

El gobierno de Salinas de Gortari, se dedicó a provocar el declive de las organizaciones de MUP, mediante el control de fondos para las viviendas públicas. En consecuencia, en 1988 el MUP perdió gran fuerza, ya que "Salinas dirigió la financiación y las reformas políticas de manera que maximizaran su capacidad de socavar a la oposición cardenista, y esto incluía alejar los fondos de las áreas donde operaba la Asamblea de Barrios" (Haber, 2008: 13). No obstante, Haber plantea la posibilidad, de que estos líderes hayan desempeñado un papel importante en estas estructuras políticas partidistas, en tanto que trajeron más beneficios para los sectores más necesitados y para la democratización. En este sentido, no puedo aseverar este planteamiento, y para ello sería prudente, a mi parecer, analizar situaciones locales, para conocer las características de la participación política de los liderazgos provenientes del MUP, incrustados en la estructura de gobierno o como participes de los movimientos sociales actuales en la Ciudad de México, lo anterior para aseverar o refutar este planteamiento. Sin embargo, no queda descartado que,

...una gran cantidad de los líderes del movimiento que sumaron fuerzas con el Partido de la Revolución Democrática (PRD) han llegado al poder en los niveles municipal, estatal y nacional, y se puede decir que han contribuido de manera importante para avanzar en la agenda de la justicia social en los gobiernos en los que han servido (Haber, 2008: 3). 
Respecto a las características de los líderes del MUP, muchos de ellos tenían una educación universitaria y a decir del Haber, dentro de la organización existían debates a niveles teóricos, que permitieron darle otras características con tintes académicos al MUP; lo anterior era perceptible en activistas de nivel medio o cuadros. Estos debates, giraban en torno a la forma en que debía llevarse la organización, y las formas de autogestión que requería un movimiento tan amplio (Haber, 2008: 9). Así pues, "Se confirió a los activistas de nivel medio la capacidad para tomar decisiones a nivel local, organizar actividades de base, negociar con funcionarios y hablar con la prensa" (Haber, 2008: 9). En este sentido, existieron cambios en la estructura del MUP que han llegado a reflejarse en las características de los movimientos sociales urbanos en la actualidad. En este momento la participación de la sociedad civil va en aumento, alimentada por la experiencia de los movimientos que le antecedieron.

EI movimiento urbano que se manifestó durante las décadas setenta y ochenta fue experimentando profundos cambios hasta convertirse en un movimiento ciudadano que está participando socialmente y exige la ampliación de derechos sociales, políticos y civiles para los habitantes de las ciudades, El movimiento urbano popular fue Ia expresión del tránsito hacia la globalización; el movimiento ciudadano resultado de aquel, es la presencia plena de la globalización (Tamayo, 1999: 501).

Así pues, se puede vislumbrar, cómo se ha transformado el MUP, a partir de la década de 1970, de un movimiento obrero a uno ciudadano. Tamayo ve esta transformación, como un proceso cíclico, que aparece de acuerdo a determinadas estructuras, condiciones históricas y culturales. Así pues, no se presenta como un alejamiento de la solidaridad y la colectividad, ya que la ciudadanía se relaciona con grupos sociales específicos y con demandas ciudadanas puntuales, que se reagrupan para exigir la expansión de una ciudadanía sustentada en derechos (Tamayo, 1999: 515). Por otra parte, la participación que han desempeñado los líderes en cada etapa de este proceso y sus transformaciones, también se han visto sometidos a cambios en su forma de ejercer sus prácticas políticas.

Los liderazgos cambiaron también dependiendo del ciclo de desarrollo de movimiento; los socialistas predominaron en la primera mitad de los setenta, los nacionalistas revolucionarios durante 1976, la corriente socialista nuevamente se hizo presente a principios de los ochenta y hasta 1987, después los nacionalistas encabezaron el movimiento durante las elecciones de 1988. Actualmente, estas ideologías han entrado en una profunda crisis: las utopías nacionalistas y socialistas han perdido credibilidad (Tamayo, 1999: 515).

Queda plantear, algunas cuestiones que provocaron el declive del MUP, y su posterior transformación a otro tipo de movilización. Este declive es propio de los ejercicios del poder del sistema político mexicano, es decir, el tipo de control de las masas, las formas clientelares y las corporativas. José Luis Reyna, citado por Núñez, menciona que corporativismo es, 
...la nucleación de grupos sociales políticamente importantes, mediante una compleja red de organizaciones políticas, al fin de hacer más sencillo, y al mismo tiempo más representativo, el proceso de toma de decisiones. La estructura política corporativa tiende a reducir la competencia por el poder y a acentuar las relaciones conciliadoras entre las diversas clases sociales, mediante su articulación vertical (Núñez, 1990: $58)$.

Ahora bien, el clientelismo que son intercambios de favores, están involucrados por las relaciones 'patrón-cliente' que Wolf citado por Alavi “clasifica como coaliciones <<verticales diádicas de entrelazamiento múltiple>> se incluyen en los alineamientos faccionales, pero sólo como uno de los distintos modos de reclutamiento" (Alavi, 1976: 91). La relación patrón-cliente se forja en las relaciones desiguales, es decir, cuando una de estas tiene el poder económico o material que lo ayudará a conservar por medio de pequeños incentivos, a sus seguidores para que sean sus apoyos en las confrontaciones y en la obtención los objetivos comunes y particulares. En este sentido los seguidores, se sienten forzados a dar apoyo incondicional, debido a los apoyos materiales que han recibido del líder.

Estas formas de clientelismo por parte del Estado, fueron una forma de desgaste al movimiento, ya que facilita a su vez, el control estatal de las agrupaciones del MUP, y a este no le queda más que solicitar el apoyo del gobierno en turno encabezado por el PRI.

La red de clientes y patrones (básicamente funcionarios) que se forman no pasa en su inserción fundamental y primera por las organizaciones burocráticas del PRI, sino que se vincula directamente con los Aparatos Unidos "locales" y centrales, que son una rama importante de la burocracia política del Ejecutivo Federal o Regional (entidades federativas). Puntualmente son también otras ramas del ejecutivo, especializadas en tal o cual servicio: Secretearía de Educación, Secretaria de Salubridad, DIF, CONASUPO, etcétera (Núñez, 1990: $63)$.

El clientelismo, también existe a nivel de los barrios en procesos de urbanización, éste se presenta de formas diferentes según el tipo de liderazgo y organizaciones a la que se pertenezca, además, estos son efectivos mientras las metas públicas no se han cumplido. En este sentido como menciona Núñez, el patrón,

...son las instituciones urbanas que poseen bienes como la regularización de la tierra, la instalación de servicios, escuelas y maestros. (...) "Los clientes" son los colonos que de manera práctica y calculada se dejan "instrumentalizar" dando voto y asistencia a manifestaciones y actos públicos a cambio de los bienes que solicitan (Núñez, 1990: 62).

Esta relación patrón-cliente, está presente también en la relación líder local y Estado, ya que aunque el líder local ha sido autonombrado e impuesto, y se comporta como un autócrata, con un grado de independencia ante el gobierno, se enfrenta al hecho que las autoridades no se comprometen con las decisiones locales dadas a conocer por ellos, empero, en esta relación, el 
prestigio del líder siempre está en juego, ya que él debe responder ante las peticiones de los colonos, y para tal fin, no puede portarse con independencia ante las instancias de gobierno de las que depende para cumplir los objetivos planteados. "Necesita "contactos", ser recibido y reconocido por ellas; hacerse de relaciones seguras e influyentes, y hacia ellos orienta toda su estrategia. Lo fundamental es conectar a su organización con las instituciones urbanas que pueden resolver el o los problemas más urgentes de su comunidad" (Núñez, 1990: 66). Los líderes, han sido intermediarios entre las organizaciones populares, y el Estado que por un periodo se portó tolerante, ya que estos líderes le ayudaron a resolver los problemas de la vivienda.

Precisamente, un líder debe tener el control de los recursos materiales que sirvan a la confrontación, y así mantener las acciones relevantes en la actividad política, además, estos recursos en manos de un líder son necesarios e importantes, en tanto interesen a los seguidores, pues también complacerán sus deseos y necesidades. Es muy importante destacar que un líder sin recursos humanos no es realmente un líder, pues un líder necesita de individuos que lo reconozcan como tal, que lo apoyen en las acciones políticas que emprenda y que estén de acuerdo con él; este recurso es precisamente lo que hace la diferencia entre un competidor, una autoridad y un jefe (Nicholas, 1969: 9).

De esta forma, para minimizar el poder de estos líderes, el Estado tomó medidas estrictas para controlar las invasiones, además de que los propietarios de la tierra distribuyen sus lotes vendiéndolos provocando que los líderes pierdan sus bases de control (Núñez, 1990: 78).

\begin{abstract}
...a partir de 1976, el Estado que ha sacado las lecciones de las primeras regularizaciones bajo Luis Echeverría, busca efectuar las regularizaciones a través de sus órganos especializados (Corett, Dartt, etcétera) o las delegaciones mismas, llamando a los colonos de manera individual y aplicando métodos de regularización más expeditos (expropiación, "inmatriculación", titulación, etcétera) que reducen la intermediación del líder. (...) Para ser reconocidos por las autoridades, entre otras condiciones tienen que incorporarse a la nueva estructura formal de la Junta de Vecinos donde su trabajo con respecto a los colonos es de control y persuasión, tocante a los planes de barrio por ejecutar, y de información con respecto a las autoridades. Sólo obtendrán bienes que distribuir... (Núñez, 1990: 79-80).
\end{abstract}

En este sentido, ésta la figura, ha perdido poder, en tanto que su presencia en muchas peticiones de servicios, o la obtención de vivienda es menos requerida actualmente, ahora las personas pueden hacer sus peticiones o trámites individualmente, incluso con el internet en plataformas especializadas, el asunto es saber, qué papel juegan ahora los liderazgos en la ciudad y cuál es el sentido de su militancia. 
Por otra parte, ante el hecho de que el Presidente de la República elegía por ley al que gobernaría la Ciudad de México, ya que ambos tenían esa doble función nacional y local por la Constitución Mexicana como alude Núñez; el Regente Hank González, publica una ley que reglamenta un sistema de representación política ciudadana, se trata del Sistema de Representación Ciudadana, que "Durante el segundo periodo de sesiones de la LII Legislatura en noviembre de 1983 el Poder Ejecutivo envió una serie de iniciativas de reformas y adiciones a la Ley Orgánica de 1979 en las que se contemplaba la creación de los órganos de colaboración vecinal y ciudadana" (Núñez, 1990: 219). En esta ley, los colonos elegían un representante de manzana que escoge a un representante de la Junta de Vecinos para que asista al "Consejo Consultivo" de la ciudad de México, sin embargo, por estar supeditado al PRI, no tenían, algún poder decisivo real, debido al nivel de clientelismo que ejercían sobre ellos. En este sentido las organizaciones del MUP, previnieron los problemas que esto les traería, "Al dirigente se le controla para que no se independice y no esté tentado en convertirse en líder tradicional, exigiéndole que informe a la asamblea de sus actividades, precisándole los problemas y demandas de los que debe ser portavoz" (Núñez, 1990: 222). Lo mismo pasó, como menciona Núñez, con las reformas administrativas y políticas al crease planes urbanos como, el Plan de Director de Desarrollo Urbano de D.F y la Secretaria de Asentamientos Humanos y Obras Públicas (SAHOP), con su plan de desarrollo urbano para colonias y barrios (Núñez, 1990: 224-225).

En torno a lo anterior, una forma de estudiar al Estado, sería justamente desde los ejercicios de poder que éste ejerce sobre los procesos micropolíticos, los abusos de poder, las formas de negociación, el clientelismo, el uso de la fuerza, las estrategias y los tipos de agrupaciones que se gestan en torno a estos procesos. Al respecto, Gledhill alude que,

Esta tesis parte de dos ideas: en primer lugar, que la sociedad civil se halla fragmentada debido a que el estado tiene una influencia limitada a escala local en áreas rurales, y, en segundo lugar que existen también unos débiles vínculos horizontales entre las comunidades locales, donde se dice que se reproducen las relaciones clientelares. La existencia de mediadores entre el nivel local y los niveles superiores se <<explica〉>, pues, de manera teleológica, como el resultado de una brecha entre los niveles de organización social y política que se debe llenar si se pretende que la sociedad y el estado funcionen (Gledhill, 2000: 203).

De esta manera, uno no se hace sin el otro, y en cierto sentido los procesos macropolíticos en los que está presente el Estado, no tienen sentido sin los procesos micropolíticos que están representados por la sociedad civil, las facciones locales, los líderes locales, los grupos etc. Ambos procesos se distinguen en los momentos coyunturales, y la antropología debería estar presente en ambos procesos ya que de lo contrario el análisis queda incompleto, pues considero 
que las formas de gobierno están en constante diálogo, es decir, el gobierno local y los gobiernos estatales. En este sentido retomo a Antonio Gramsci, referido por el abogado Carlos Pereyra, el cual menciona que Gramsci es uno de los primeros en plantear la cuestión del cambio revolucionario y que su conceptualización tiene que ver con los cambios coyunturales. De esta forma, Gramsci aludido por Pereyra, retoma el concepto de sociedad civil,

...empleado para aludir a una diversidad de organismos a través de los cuales los miembros de la sociedad se integran en la actividad política y en el debate ideológico [...]. Se pueden fijar dos grandes planos superestructurales, el que se puede llamar de la "sociedad civil", que está formado por el conjunto de los organismos vulgarmente llamados "privados" y el de la "sociedad política o Estado (Gramsci, 1972: 16)" (Pereyra, 1998: 53).

La relación de la sociedad civil respecto al Estado, radica en el hecho de que si bien no pueden estar separadas, tampoco llegan a fusionarse de tal forma que parezcan iguales, con las mismas funciones y representantes del mismo poder, así pues como alude Gramsci citado por Pereyra,

La primera conclusión, pues, sobre la pareja Estado-sociedad civil es que de ninguna manera pueden concebirse estas entidades como separadas, con un funcionamiento exterior de una respecto a la otra" (Pereyra, 1998: 54) [...]. Hay, sin duda alguna, vinculación orgánica entre Estado y sociedad civil, pero de ello no se infiere que ésta se desvanece hasta confundirse con aquél. [...] Medios de comunicación, centros educativos, sindicatos, organismos eclesiales, etcétera, no son "aparatos ideológicos de Estado", son instituciones ideológicas y políticas de la sociedad civil cuyo funcionamiento se deslinda de los dictados gubernamentales en la medida en que son espacios abiertos a la lucha de clases (Pereyra, 1998: 55).

Pereyra menciona que Gramsci acude a la expresión de "hegemonía política", y que hace hincapié en que la hegemonía está presente en la sociedad civil y el Estado. Además alude que la sociedad civil posee un potencial coercitivo que no está manifiesto en tiempos de paz, en este sentido me parece semejante a las propuesta de Gledhill, que menciona que en un momento de coyuntura, pueden vislumbrarse ciertos procesos micro políticos, así también, el Estado se percibe más en momentos de coyuntura, que es el momento en que converge con lo local “...la tercera conclusión sobre la pareja terminológica Estado-sociedad civil consiste en rechazar el reparto simétrico de coerción y consenso en cada lado de la pareja. El Estado es un aparato represivo y, a la vez, generador de consenso y fuente de hegemonía" (Pereyra, 1998: 59-60). La sociedad Civil, por lo mencionado anteriormente,

...ha ido construyendo empíricamente un subsistema de intermediación entre los colonos de la periferia y el gobierno de la ciudad (...) En sí misma parecería que la creación de estas organizaciones clientelares es la construcción, al menos embrionaria, de organizaciones inmediatas y de tipo asociativo entre la Sociedad Civil de estos medios y el Estado, Sí lo son de modo muy elemental a pesar de estar fuertemente marcadas por hábitos culturales tradicionales (Núñez, 1990: 84-85). 
Por otro lado, Como menciona Oscar Núñez, se ha debatido cuáles han sido las condiciones sociales que hacen posible la movilización de grandes grupos, algunas corrientes apostaban que era la situación de masa "Esa masa atomizada, mediocre vulgar y carente de conciencia histórica, pretende dirigirse a sí misma o es fácil presa de los dirigentes llamados "los terribles simplificadores" (Núñez, 1990: 27). En el caso de los líderes esta corriente de masas los percibe como "Líderes improvisados e ignorantes dirigen demagógicamente a masas apáticas atomizadas, desencadenando en ellas un activismo orientado según los intereses de los líderes. Grandes agregados humanos, sin sólidos vínculos culturales se someten así a líderes fuertes” (Núñez, 1990: 28).

Respecto a lo anterior, retomo los conceptos de "la consciencia contradictoria" y la "creatividad cultural" de Gramsci, retomados por Kate Crehan, que a su vez utiliza el concepto del "hombremasa activo",

Casi se puede decir que [el hombre-masa] tiene dos consciencias teóricas (o una consciencia contradictoria), una implícita en su quehacer y que le une realmente a sus camaradas en la transformación práctica del mundo real, y otra superficialmente explícita o verbal que ha heredado del pasado y ha interiorizado acríticamente (SPN, p. 333; citado en Gutmann, 1996, p. 14). [...] La contradicción entre la visión del mundo de un grupo dominante (cuya dominación se apoya en última instancia en su posición económica dominante y en la explotación económica de los dominados) y una visión implícita, aún inarticulada, de «cómo son las cosas» según los dominados (Crehan, 2002: 213-214).

Lo anterior, viene de una contradicción fundamental entre las clases, que generan desigualdad, en donde para Gramsci, la clase es “...una forma de analizar pautas sistemáticas de desigualdad, que se reproducen en el tiempo, y que presentan de mil maneras distintas un sesgo étnico y de género, etc." (Crehan, 2002: 217-218).

Una dimensión crucial de esa vivencia de clase son las relaciones de poder concretas. El concepto de hegemonía nos ayuda a entender cómo se vive el poder en un contexto dado, y cómo se producen y reproducen ciertos regímenes de poder -recordemos que no hay régimen sin contestación- en la vida cotidiana de los individuos. [...] Es, pues, un concepto que rechaza cualquier tipo de jerarquía simple entre la base y la superestructura. Yo diría que es precisamente ese rechazo lo que hace de la hegemonía una herramienta tan potencialmente fructífera para abordar el tema del poder (Crehan, 2002: 222-223).

El tipo de postulados para la dirigencia política, que se fue transformando en el MUP, a partir de algunas corrientes teóricas, pero también a partir de la experiencia en el movimiento, como menciona Oscar Núñez, influyó para que los militantes pasaran de un tipo de liderazgo en donde se hablaba de forma autoritaria, en el que éste tomaba las riendas y las decisiones del movimiento junto con los demás dirigentes de su confianza, en el cual las personas deben acatar sus órdenes bajo la amenaza de perder su predio; a otro tipo de liderazgo, en el que hay una 
rotación en las presidencia de la asamblea, las decisiones se toman en votación, a mano alzada, en donde las mujeres participan, existe una información más compartida entre las personas, que se puede debatir, existe por así decirlo, una toma de conciencia y se forja una identidad en la participación política (Núñez, 1990: 203).

Esta nueva forma de participación, si bien trajo beneficios a las personas, no quiere decir que estas no hayan ejercido anteriormente un tipo de participación política, ni que no hubieran tenido agencia para la participación, a mi parecer, fue justamente debido al impulso del movimiento y al relajamiento de parte de los liderazgos, sin amenazas, que las personas se sintieron con la libertad de ejercer su poder y sobretodo fueron adquiriendo experiencia en la participación, un conocimiento que obligó a los liderazgos a modificar su ejercicio del poder. "Estos mismos militantes permiten reducir los costos del proceso de decisión, en función de su calidad: Ayudar a saber diferenciar lo importante de los secundario en el terreno de las reivindicaciones urbanas. A través de ellos se transmite la memoria colectiva del MUP oral y escrita; se aprende a analizar la coyuntura política” (Núñez, 1990: 208). La experiencia en la práctica, permite agilizar y hacer más eficientes las acciones del movimiento, el conocimiento de las técnicas de dinámica de grupo; las pedagogías concientizadoras no son innatas "vemos florecer la democracia de base, que es uno de los cambios de la cultura popular de estos medios más importante" (Núñez, 1990: 208).

En este sentido, al mismo tiempo de observar un proceso político, podemos percatarnos de la existencia de un proceso de análisis teórico, respeto a los movimientos sociales que han guiado al MUP y su transición política. Así pues describiré brevemente tres enfoques que han analizado a los movimientos en México. El enfoque Marxista, presente en las primeras etapas del MUP, realiza una crítica al capitalismo desde el liberalismo, el Estado y la cultura, reduciendo así el espectro analítico a la dictadura del proletariado, en este sentido, la crítica al liberalismo se concentra en la detracción de la democracia; para este enfoque, las estructuras políticas partidistas eran dependientes de la estructura económica dominante, además el Estado era el enemigo, centrándose en la lucha armada que no tuvo éxito (Iturbide, 2013: 14-17). Una manifestación de este enfoque como menciona Iturbide que sigue a Alarcón, lo encontramos al “...enmarcar los movimientos sociales de las décadas de 1960, 1970 y hasta 1980, como "obreros", o tendientes a serlo, cuando la observación constataba su composición diversa y con objetivos que poco o nada tenían que ver con una "dictadura del proletariado (Alarcón, 2001: 
144)" (Iturbide, 2013: 18). De esta forma como menciona el antropólogo Iturbide, las ciencias sociales como la antropología y la sociología, miraron hacia los aportes sociológicos inclinados a una perspectiva cultural al ver los movimientos sociales como acciones colectivas (Iturbide, 2013: 19).

El segundo enfoque que retomaré, es la sociología de la acción, en donde hay tres tipos de acción, la acción colectiva, el movimiento social, y el conflicto. En este enfoque, existen dos posturas de la acción colectiva, la primera, la concibe como una unidad previamente establecida dando por cierto atributos del movimiento. La segunda, perspectiva, "sugiere ver a la acción política como el resultado de la convergencia de fines, recursos y límites a través de un sistema de acción multipolar. Siendo uno de sus representantes el sociólogo italiano Alberto Melucci” (Iturbide, 2013: 21). En esta segunda perspectiva, existen tres tipos de acción colectiva, de solidaridad, de agregación y de desviación que pueden emerger por la presencia de un conflicto o bien por el consenso. Según Eduardo Nivón que sigue a Melucci, citado por Iturbide, las dimensiones analíticas que definan al movimiento social, están cimentadas por la solidaridad, sostenidas por un conflicto, y buscan la ruptura de la compatibilidad. Además Iturbide alude, siguiendo a Melucci, que existen tres fases del movimiento social la reivindicativa, la fase política, y la fase antagónica (Iturbide, 2013: 21).

Así llegamos a la movilización de recursos en donde

La propuesta general sugiere estudiar el cómo se consiguen las metas que se propone el movimiento social a partir de ciertos recursos con los que cuenta dicho movimiento como es: a) la composición de la dirigencia; b) el inventario de los recursos humanos y materiales de que disponen; c) el contexto político; d) la variedad de acciones que ejecutan y; e) cómo a partir de la combinación de los anteriores elementos los movimientos llegan a alcanzar o no, sus objetivos (Iturbide, 2013: 26).

A partir de estos tres enfoques, se han desarrollado otros, que no será posible incluir en este ensayo, sin embargo a partir de éstos, podemos tener otra mirada del rumbo teórico y metodológico que ha llevado el MUP a su transición al MOSU. No obstante tomaré la definición de Alberto Melucci para manifestar que,

De tal manera, los movimientos sociales son sistemas de acción en el sentido de que cuentan con estructuras: la unidad y continuidad de la acción no serían posibles sin la integración e interdependencia de individuos y grupos, a pesar de la desestructuración aparente de estos fenómenos sociales. Pero los movimientos son sistemas de acción en el sentido de que sus estructuras son construidas por objetivos, creencias, decisiones e intercambios, todos ellos operando en un campo sistémico. Una identidad colectiva no es sino una definición compartida del campo de oportunidades y constricciones ofrecidas a la acción colectiva (Melucci, 1999: 37). 
En ocasiones, la antropología acostumbrada a estudiar a las culturas, frecuentemente se casa con la idea de que éstas son rígidas, inmutables y con márgenes establecidos e impenetrables, y desde esta idea, la antropología no puede estudiar al Estado y a los movimientos sociales, así pues, es conveniente flexibilizar y operativizar los conceptos con los que la disciplina ha trabajado, conceptos como cultura o historia se van ampliando, así pues, Wolf citado por Crehan, menciona que las culturas

...no había que verlas como hechos dados, integrados por una especie de esencia interna, razón organizativa o plan maestro, sino como conjuntos culturales, y como conjuntos de conjuntos, que se construyen, destruyen y reconstruyen continuamente, bajo el impacto de múltiples procesos que operan en grandes espacios de conexiones sociales y culturales $(2001$, p. 313) [...]. Lo que la atención a la historia hace posible es observar cómo los procesos se desencadenan, se entremezclan, se despliegan y se diluyen con el tiempo. Significa repensar las unidades de nuestras indagaciones -familias, comunidades, regiones, entidades nacionales- y verlas no como entidades fijas, sino como entes problemáticos: que se configuran, se reconfiguran y cambian en el tiempo (2001, p. 390) (Crehan, 2002: 198).

Ahora bien, es pertinente preguntarnos, cuáles han sido los cambios del tránsito del MUP al MOSU, específicamente en la actividad política de los liderazgos y militantes, en las Colonias de la ciudad de México. Para la antropología sería pertinente contestar estas preguntas desde cada realidad local. Lo anterior a partir del hecho de que cada realidad tiene sus especificidades, aunque se pretenda la construcción de una sociedad homogénea, “... aún entonces siempre subsisten elementos vivos y actuantes de los otros modelos, siempre están presentes hábitos e ideologías prácticas no plenamente sometidos a la lógica dominante, que explican el carácter incoherente y contradictorio del comportamiento de los grupos y de los individuos" (Núñez, 1990: 16).

Los avances políticos que se logran en el largo recorrido de lucha, crea en todos estos afiliados y con mayor razón en los militantes, una conciencia política que es sin duda uno de los logros más importantes de los MUP, conciencia que perdura aun cuando aparentemente todo ha terminado, al menos en buena parte de la población. Esta Conciencia Política podemos denominarla CONCIENCIA CIUDADANA POPULAR (Núñez, 1990: 102).

En la actualidad, existe un discurso globalizado, en torno a problemáticas sociales, que ha permitido la posibilidad de comunicación e interacción social y política más allá de lo local, no obstante también se construyen al mismo tiempo, en la interacción cotidiana, una serie de códigos, signos y símbolos, necesarios para la construcción cultural y política de cada localidad. En este proceso también está presente un tipo de cultura política, que se percibe en el momento en que se quiere analizar las características de la participación política de los liderazgos, miembros de base y militantes que han estado presentes en este proceso de transición, y en este 
sentido podemos percatarnos “...cómo los procesos de escala local no sólo reflejan otros procesos políticos mayores y conflictos de escala nacional, sino que pueden contribuir a ellos" (Gledhill, 2000: 203). Con lo anterior, me parece que se vislumbra la capacidad de incidencia que tienen los grupos, las localidades, las comunidades, las colonias, de tal forma que, es probable que se les pueda restar interés al no pensarlos como posibles actores de cambio. Así pues, el Estado también se puede analizar, a partir de las demandas y acciones de lo local, para lograr objetivos que hacen que éste modifique sus acciones o seda a las peticiones, es decir, podremos saber, hasta dónde el Estado es capaz de llegar tras las presiones o las negociaciones, hasta dónde el imaginario de la sociedad, vislumbra sus posibilidades y se pregunta, qué alcance tienen sus demandas más allá de sus procesos micropolíticos en lo local.

En torno a lo anterior, aludo que, existen características culturales que han servido para la consecución de metas públicas, que se han puesto a la disposición de los movimientos y han hecho posible la transición. Estos elementos culturales, se han ido transformando y se han adaptado al proceso político propio del MUP. En este sentido, a partir de 1950, en México se presentó un momento de cambios culturales, sociales e históricos, a partir de que se intensificó la migración a la ciudad, ya que éstos migrantes que se incorporaron a la urbe, provenientes de distintas partes de la República, tenían un repertorio de hábitos, creencias, actitudes, motivaciones, prácticas y costumbres, que si bien tenían características diferentes, traían algunos códigos que les eran comunes, como la reciprocidad, valores, practicas sexo-genéricas, un sentimiento de unidad y vínculos culturales, emocionales y de parentesco; en este sentido, experimentaron un momento liminal, en el sentido que Víctor Turner lo describe,

El tema en cuestión viene representado en primer lugar por la naturaleza y características de lo que Arnold van Gennep (1960) ha denominado la «fase liminal» de los rites de passage. El mismo Van Gennep los definió como «ritos que acompañan todo cambio de lugar, estado, posición social y edad». Para indicar el contraste entre «estado» y ((transición», empleo el término «estado» para referirme a todas sus otras acepciones; es un concepto más global que status o «cargo», y designa cualquier tipo de condición estable o recurrente cultural- mente reconocida. Van Gennep ha demostrado que todos los ritos de paso o «transición» se caracterizan por tres fases, a saber: separación, margen (o limen, que en latín quiere decir $<\langle$ umbral») y agregación. La primera fase (de separación) comprende la conducta simbólicas por la que se expresa la separación del individuo o grupo, bien sea de un punto anterior fijo en la estructura social, de un conjunto de condiciones culturales (un «estado»), o de ambos; durante el periodo «liminal» intermedio, las características del sujeto ritual (el «pasajero») son ambiguas, ya que atraviesa un en- torno cultural que tiene pocos, o ninguno, de los atributos del estado pasado o venidero, y en la tercera fase (reagregación o reincorporación) se consuma el paso. El sujeto ritual, ya sea individual o colectivo, se haya de nuevo en un estado relativamente estable y, en virtud de ello, tiene derechos y obligaciones vis a vis otros de un tipo claramente definido y «estructural» (Turner, 1988:101). 
Este es el momento en el que hombres y mujeres, en el lugar al que llegaron, son señalados de muchas maneras y de ninguna en específico, era un momento de transición en la que no habían tomado forma concreta social ni política, ellos mismos estaban viviendo en una coyuntura, sin una identidad aparente, y estaban participando en un rito de paso para convertirse en los nuevos habitantes legítimos de la ciudad. Es por tal motivo que retomo el concepto de liminal para calificar este proceso de transición,

Los atributos de la liminalidad o de las personae liminales (<<gentes de umbra〉〉) son necesariamente ambiguos, ya que esta condición y estas eluden o se escapan del sistema de clasificaciones que normalmente establecen las situaciones y posiciones en el espacio cultural. Los entes liminales no están ni en un sitio ni en otro; no se les puede situar en las posiciones asignadas y dispuestas por la ley, la costumbre, las convenciones y el ceremonial. En cuanto tales, sus ambiguos e indefinidos atributos se expresan por medio de una amplia variedad de símbolos en todas aquellas sociedades que ritualizan las transiciones sociales y culturales (Turner, 1988:102).

En este sentido, en un primer momento, en el que acontecía un proceso de incorporación o adaptación como habitantes de una ciudad a otros grupos, estas personas tenían un doble carácter, es decir, uno como miembros de una comunidad y otro, como miembros de una agrupación política; son identidades de tipo asociativo en donde la segunda requirió un proceso de aprendizaje, un carácter distinto de politización requerida para el MUP. En esta nueva identidad política, cuyo proceso también es liminal, fue en la que el MUP se fue consolidando, y es probable que en este primer momento, como menciona Oscar Núñez, existiera situación social de masa, en donde las personas pareciera que pierden el sentido de sus agrupaciones, se disuelven en solidaridades de clase, las personas no se sienten integradas y desconocen los procesos políticos por el que pasan, de tal forma que necesitan un líder que les diga qué hacer, de tal forma que,

En los barrios periféricos que comienzan, no se han creado (si alguna vez se van a crear) nuevas identidades y comunidades de nuevo tipo asociativo que reemplacen la coherencia cultural perdida. En los inicios no se tiene más que la familia nuclear y extensa, el "paisanaje" y redes vecinales que se tejen lentamente a través de todos los mecanismos de sobrevivencia... (Núñez, 1990: 33).

Si bien, en este tránsito, se ha individualizado la sociedad, el mercado capitalista ha empleado personal que no tiene tiempo para la participación política, la tecnología ha modificado la manera en que las personas se relacionan, se han perdido algunos vínculos comunitarios, prácticas, hábitos y valores; el sentimiento de unidad se ha ido transformando pero no se ha perdido, aunque de formas distintas, adaptadas a las nuevas realidades, aludo que este ha sido clave para que las movilizaciones se sigan dando y permitió entonces que hubiera una transición de un modelo de movimiento a otro, es decir, del MUP al MOSU. 
La migración a la ciudad no se hizo de manera individual, los migrantes llegaron a la ciudad ya sea con padres y hermanos, o casados con o sin hijos, además se unían a ellos otros parientes, compadres, amigos que llagaban a alojarse a la casa de los primeros que llegaban, de tal forma, que los migrantes contaban con lazos sociales relacionados a la estructura de parentesco, con la cual venían acostumbrados a relacionarse. Esta extensa red social de parentesco, tuvo un papel crucial para la participación política, es decir, entre ellos se apoyaban para poder participar y ser apoyos de líderes, que necesitaban de esas redes para fortalecer los movimientos. Así pues, la tenencia será para ellos mantenerse como una familia extensa, salvo en el caso de ascenso social o económico como lo menciona Larissa Lomnitz (Lomnitz, 1975:216). Las unidades domésticas, incluso al día de hoy se componen de varios núcleos familiares, y aunque ahora es un lugar, en donde se localiza también la reproducción ampliada de la fuerza de trabajo, aún las mujeres desempeñan un rol específico parecido al de su llegada a la Ciudad.

En el MUP, la mujeres desempeñaron un papel muy importante ligadas a "Las circunstancias objetivas de instalación difíciles y progresivas en el barrio, la ausencia de equipamientos cercanos (mercados, escuelas, centros de salud) y de servicios, obligan a la mujer a permanecer en casa" (Núñez, 1990: 38). Esta situación permitió que ellas pudieran desempeñar un papel estratégico en las actividades del MUP, en los terrenos que fueron invadidos, en las periferias de la ZMCM. Así pues, se percibe una extensión del trabajo doméstico, con fines de participación política.

Un elemento dominante y organizador de las necesidades en estos grupos, fue la consecución de un terreno para vivir, y posteriormente la obtención de servicios públicos para la vivienda. En el ámbito rural es normal vivir en la casa de los padres y después heredar, era y aún sigue siendo, aunque menos constante, una costumbre vigente. También estaban acostumbrados a la autoconstrucción, autogestión o autoproducción de la vivienda, se percibe una carga valorativa a la tierra y la casa, como unidad doméstica, en donde se reproducen las prácticas sociales importantes para mantener la cohesión y hacer más fácil el tránsito de la vida. Así pues, en este aspecto, han habido modificaciones respecto al ámbito rural "Hasta fecha reciente la casa era casi exclusivamente un valor de uso. Ahora se ha descubierto que no sólo la casa puede transformarse en valor de cambio, sino que su valor aumenta continuamente de precio por la plusvalía del suelo" (Núñez, 1990: 40). 
Algunas prácticas heredadas de ese contexto, han permitido la consecución de las metas públicas dentro del MUP, y los líderes se encargaron de explotar estas creencias y prácticas, para tal motivo. De esta forma, existe otro concepto que permite dar explicación a este tipo de vínculos, me refiero al termino "communitas" que ha desarrollado Víctor Turner, este alude a un vínculo social que se genera en una cierta estructura o grupo social,

Lo que nos interesa de los fenómenos liminales para los fines que aquí perseguimos es la mezcla que en ellos se observa de lo humilde y lo sagrado, de la homogeneidad y el compañerismo. En tales ritos se nos ofrece un ((momento en y fuera del tiempo)), dentro y fuera de la estructura social secular, que evidencia, aunque sea fugazmente, un cierto reconocimiento (en forma de símbolo, si no siempre de lenguaje) de un vínculo social generalizado que ha dejado de existir pero que, al mismo tiempo, debe todavía fragmentarse en una multiplicidad de vínculos estructurales. Estos son los vínculos que se organizan en términos o bien de casta, clase o jerarquías de rango o bien de oposiciones segmentarias (Turner, 1988:103).

En este proceso dentro del MUP, los líderes y dirigentes quisieron simular una communitas, para fines políticos, ya que sí existía una estructura política jerarquizante, alimentada por algunas teorías de masas y por el nivel escolar que algunos tenían dentro del movimiento, o por el prestigio de los líderes, no obstante este tipo de liderazgos ha ido transformando su tipo de ejercicios de poder, así pues,

Parece como si existieran aquí dos «modelos» principales de interacción humana, yuxtapuestos y alternativos. El primero es el que presenta a la sociedad como un sistema estructurado, diferenciado, y a menudo jerárquico, de posiciones político-jurídico-económicas con múltiples criterios de evaluación, que separan a los hombres en términos de «más»o «menos». El segundo, que surge de forma reconocible durante el período liminal, es el de la sociedad en cuanto comitatus, comunidad, o incluso comunión, sin estructurar o rudimentariamente estructurada, y relativamente indiferenciada, de individuos iguales que se someten a la autoridad genérica de los ancianos que controlan el ritual. Prefiero la voz latina communitas a «comunidad», para distinguir esta modalidad de relación social de un ((ámbito de vida en común)) (Turner, 1988:103).

Estas personas, aún seguían implementando algunas estrategias de sobrevivencia, que aprendieron en sus lugares de origen y las replicaron en la Ciudad, no obstante otras las aprendieron en los momentos de necesidad, durante su militancia en el MUP y más tarde fue parte del repertorio de experiencias que en un futuro los hizo adaptarse a otro tipo de participación política. Lo anterior, lo relaciono con el sistema de prestaciones totales o potlatch como lo denomina Marcel Mauss, que se refiere al,

...carácter voluntario, por así decirlo, aparentemente libre y gratuito y, sin embargo, obligatorio e interesado de esas prestaciones; prestaciones que han revestido casi siempre la forma de presente, de regalo ofrecido generosamente incluso cuando, en ese gesto que acompaña la transacción, no hay más que ficción, formalismo y mentira social, y cuando en el fondo lo que hay es la obligación y el interés económico (Mauss, 1979:157).

En este tipo de economía, se intercambian bienes, riquezas o productos y no se da mediante la compra, "No son los individuos, sino las colectividades las que se obligan mutuamente, las que 
cambian y contratan. (...) Estas prestaciones y contraprestaciones nacen de forma más bien voluntaria por medio de presentes y regalos, aunque, en el fondo, sean rigurosamente obligatorias bajo pena de guerra privada o pública" (Mauss, 1979:160). Los nuevos habitantes de la ciudad, estaban obligados a ayudar a un vecino en un momento de necesidad, ya sea con bienes materiales, provisiones de alimentos, cuidar a sus hijos o favores, como ayudar a construir o instalar sus viviendas, así pues, como menciona el autor "Este tipo de derecho y de Economía contiene diversos temas, reglas e ideas. El más importante de estos mecanismos espirituales es evidentemente el que obliga a devolver el regalo recibido" (Mauss, 1979:162).

El honor de dar y devolver los favores, era carta segura para la sobrevivencia, una mala fama correspondería a la posibilidad de no concretar con éxito, el objetivo de permanecer en el territorio y obtener un terreno para vivir. En este tipo de sistema económico o Potlatch, tomado como referencia para el MUP, queda en la memoria con un profundo agradecimiento en las personas que supieron dar, recibir y devolver, ya que aunque las cosas materiales ya no existen, o fueron provisionales, como por ejemplo, laminas, madera, piedras, alimentos, presentes etc., éstas se quedan en el recuerdo, así como las acciones en forma de ayuda, cuidados, palabras de aliento, consejos, defensa contra el enemigo etc. Toma como menciona el autor un carácter de poder espiritual que une en momentos de conflicto y peligro.

Este hecho aclara dos sistemas importantes de fenómenos sociales en Polinesia e incluso fuera de ella. En primer lugar, permite averiguar cuál es la naturaleza del lazo jurídico que crea la transmisión de una cosa. (...) Sirve además para darse cuenta mejor de cuál es la naturaleza del cambio por medio de dones, de cuál es la naturaleza de lo que nosotros denominamos prestaciones totales, y entre ellas, la del potlatch (Mauss, 1979:168).

Este tipo de economía tiene un tipo de moralidad que se ha mantenido vigente desde el MUP a los MOSU, aunque las ciudades exijan la adaptación a los modos de la economía capitalista, y se perciba la individualidad que ha traído inestabilidad a la sociedad. Este sistema económico al que estaban acostumbrados los migrantes en sus lugares de origen la desarrollaron como una habilidad y una práctica, para la sobrevivencia, también la utilizaron los líderes dentro del MUP. Es una práctica que ha permitido la transición y la continuidad a los MOSU, es un legado del MUP.

Es posible extender estas observaciones a nuestras propias sociedades. Una parte importante de nuestra moral y de nuestra vida se ha estacionado en esa misma atmósfera, mezcla de dones, obligaciones y de libertad. Felizmente no está todavía todo clasificado en términos de compra y venta. Las cosas tienen todavía un valor sentimental además de su valor venal, si hubiera valores que se pudieran clasificar sólo como de este tipo. Tenemos otras morales además de la del mercader; todavía hay gentes y clases que se conservan en las costumbres de otros tiempos, costumbres a las que todos nos sometemos, al menos en algunas épocas o en algunas ocasiones del año (Mauss, 1979: 246). 
Un tanto en relación a lo anterior, un líder se creaba en un contexto de 'lealtades primordiales' que son aspectos de la organización social que no se concentran sólo en la familia, sino también en grupos corporativos de parientes, linajes y autoridades (Alavi, 1976: 68), se centran en normas culturales, se fortifican mediante las emociones y sentimiento que se tejen alrededor de individuos, grupos, instituciones, etc., y no toman en cuenta las contradicciones entre estos (Alavi, 1976: 61). En correlación a lo anterior, Alavi sugiere que "los mecanismos de $<<$ control social〉> no operan de forma mecánica y automática, sólo en relación con las normas y las reglas, sin tener en cuenta el poder de las clase de personas en el sistema político local y nacional" (Alavi, 1976: 73).

Ahora bien, como ya se ha venido desglasando, a partir de la década de 1990, comienza un cambio en la participación política de las personas, diferente al que se había reflejado hasta entonces, y que en gran manera provenía del MUP, desatado en la década de 1960. Como menciona Victoria, entre 1992 y 1995 se hicieron presentes detonadores que permanecerían largo tiempo, entre ellos el Tratado de Libre Comercio (TLC) y a nivel comercial, la tercerización sobresalió de otros tipos de economías, y se garantizó la inversión global por medio de vías jurídicas, "La ciudad de México iniciaba una gran transformación cuando ya era una de las ciudades más pobladas del mundo y con fuertes déficits de infraestructuras básicas y desequilibrio ecológico" (Álvarez, 2016:10).

La ciudad se convierte en un escenario de nuevos reclamos y condiciones de vida, el llamado "derecho a la ciudad", ha sido utilizado como demanda por distintos grupos, y ha permitido develar el cúmulo de problemáticas presentes en la ciudad, estas demandas han sido propensas a formar nuevos tipos de ciudadanía, "En los intersticios de las fuertes polaridades de la ciudad moderna surgen iniciativas de la sociedad civil a través de las cuales se cuestionan los procesos globalizadores en diversos planos, buscándose generar formas de pertenencia, nuevas propuestas de desarrollo urbano y estrategias diversas de sobrevivencia" (Álvarez, 2016:10). Así pues la complejidad de la vida urbana contemporánea suaviza la relación tradicional entre ciudadano y Estado-nación.

Los medios financieros e inmobiliarios, se hicieron tendencia en América Latina y México es el mercado más activo en este rubro, el boom inmobiliario se concentró en la Ciudad de México, como menciona el antropólogo Carlos San Juan Victoria, este boom coincidió con la oleada de 
las "ciudades globales" en la década de 1990, y coincidió con que esta ciudad fuera el centro administrativo y político de la nación y con sus instituciones de representación política (Álvarez, 2016:19). "Por un lado su rediseño como eslabón estratégico para los flujos de la globalidad, y el de reconvertir los recursos naturales, el suelo urbano y rural, las producciones físicas e inmuebles de la ciudad y la nación en "activos financieros" volátiles. En sentido estricto, es una “ciudad global” (Álvarez, 2016:19).

En México, había elites interesadas en la poderosa lógica geopolítica de Estados Unidos, y a partir del TLC trajo a interesados en los servicios, la articulación material, territorial y productiva, además aprovecharon una nueva mercantilización del suelo urbano que se puede apreciar en edificios, plazas comerciales, primero en las delegaciones con mayor infraestructura urbana y luego se extendieron hacia otros lugares, el sector inmobiliario tuvo su auge entre 2002 y 2007, su crisis en 2008 y su realce en 2010 (Álvarez, 2016:23). "Esta expansión que reorganiza a la ciudad en su conjunto ocurrió bajo el control de los gobiernos federales y locales del PRI hasta 1997, y de entonces a la fecha entre los gobiernos federales del PRI y del PAN y el gobierno de izquierda del PRD en la ciudad" (Álvarez, 2016:24).

Menciona el antropólogo Victoria, que aún pesaba el recuerdo de 50 años atrás, en donde hubo una producción social de la vivienda, para migrantes ilegales que tomaban posesión de tierra de forma ilegal, y yo creo que también se quedó en el recuerdo, la prosperidad económica vivida después de la época de gran industrialización del país.

Pesaban los tejidos sociopolíticos que la permitían por clientelismo o por presión social que conquistaba espacios. Y una tradición de urbanismo, de movimientos sociales, arquitectos y funcionarios públicos, que crearon fuertes referentes de planeación urbana considerando esa producción social y la capacidad de los ciudadanos para incidir en las decisiones públicas en relación con los usos del suelo (Álvarez, 2016:25).

De lo anterior, se desprendieron medidas federales para la planeación de la urbe, que ya estaba saturada, entre estas medidas, como menciona Victoria, se implementó el programa parcial de Zonas Especiales de Desarrollo Controlado (Zederec), en donde se regulaban los usos del suelo y había políticas de producción de vivienda; después se presentó la revitalización del mercado inmobiliario, para atenuar la vivienda popular, resolver invasiones y empresarios clandestinos del uso del suelo de conservación; después vino la reactivación del gasto público, en grandes obras urbanas, como vialidades elevadas, nuevas líneas del metro y autopistas, para fomentar el boom inmobiliario, inversión que provino del gobierno federal y empresarios privados; la creación del sistema privado del horro para el retiro (Consar) que dio, impulso al boom 
inmobiliario; la Ley de Cultura Cívica del DF, aprobada en 2004 encaminada a la tolerancia cero que criminaliza a la pobreza el empleo informal de espacios públicos; la Ley de Desarrollo Urbano del entonces DF, aprobaba en julio de 2010, reduce las formas y espacios de participación ciudadana y facilita la intervención del sector privado, también hubo apoyos e inversiones entre dinero público y privado; por parte de ex jefe de gobierno Miguel Ángel Mancera que anuncio la Reforma del reglamento de construcción de la Ciudad, que elimina 14 causales de suspensión de obra (Álvarez, 2016: 28-29).

Ante estos hechos, ha existido 1.7 millones de familias expulsadas de la Ciudad debido al incremento en el costo de la vida, además se ha presentado un deseo de consumo, a costas de deudas a largo plazo "Una liberación del deseo achicado al mundo mercantil, una forma de "libertad" de elección que se disciplina a la forma hegemónica de la ciudad. Las ideologías políticas se diferencian por las rutas para conseguir lo mismo" (Álvarez, 2016: 29). Se ve un cambio en las zonas de vivienda familiar, rodeadas de edificios, plazas y comercios, se presenta una transformación en la forma de vida en los barrios populares, se han tejido relaciones de desigualdad, estos cambios han ocurrido en manos de gobierno que se autonombran de izquierda; y para estos grupos "Una ciudad para todos", concentraba el sentido de constelaciones plurales integradas por movimientos urbanos, intelectuales, partidos y cuadros de gobierno para crear a contrapelo del agresivo neoliberalismo, otra manera de gobernar y orientar a la ciudad" (Álvarez, 2016: 31).

Los movimientos urbano-populares y las organizaciones civiles ciudadanas se construyeron en la oposición y ejercieron su autonomía durante los años setenta del siglo pasado bajo el dominio de los gobiernos priístas. Fueron actores decisivos de la transición política y parte de una coalición política y social conquistó el gobierno en 1997. Ahí se crearon generaciones aún vigentes de liderazgos, culturas sociales y políticas que han permitido que en la ciudad existan segmentos organizados e insertos en las políticas de gobierno, con capacidades ciertas de interlocución y negociación, que se alimentaron de experiencias sociales y políticas en ocasiones como dirigentes partidarios o ya como funcionarios de gobierno (Álvarez, 2016: 38).

A decir de Carlos Victoria, de ahí surgieron tres rasgos de cultura política, el primer rasgo viene de la colaboración con sus gobiernos, que se dio en un momento de reinvención gubernamental, las gobernanzas sociales y la coincidencia con políticas concretas, alude que paso de las movilizaciones en las calles, a las colas de los peticionarios en las dependencias gubernamentales. El segundo rasgo, tiene que ver con que el espectro de convocatoria social se fue especializando hasta formar un fenómeno distinto característico de las modernidades actuales característica de las negociaciones neocorporativas. 
Finalmente, entre las políticas sociales focalizadas y la población se crearon estructuras de control territorial en manos de liderazgos, funcionarios de partidos, diputados locales, delegados, funcionarios de gobierno, inscritos en la política social, capas de intermediarios expertos en la gestión social que propician redes de control del "voto duro" o que al menos aspiran a ello, y que permite ganas las votaciones internas del partido y preparar su base electoral en caso de ser favorecidos con alguna candidatura de elección popular" (Álvarez, 2016: 39).

Podemos observar, una estructura política que se conforma de un ejercicio de poder parecido al MUP, pero con nuevos elementos, en donde realmente la sociedad civil pierde peso. Se siguen ejerciendo prácticas clientelares, de partidos que se asumen de izquierda y caen en el deseo de enriquecerse, se beneficia a clases altas, y se encubren bajo la implementación de oficinas para la atención ciudadana, o los foros para construir ciudadanía o la supuesta democracia en cada proceso electoral. Victoria menciona, que se presenta una reflexión crítica parecida a los setenta en el que cuadros de intelectuales, profesionales, periodistas críticos, cuadros de gobierno, se ven inmersos en una lucha contra el partido hegemónico en ese entonces, sin embargo ahora se puede ver también con partidos de izquierda, cuyos dirigentes proceden de una lucha urbano popular. Lo anterior hace que el enemigo dentro de los movimientos sea toda la estructura política y de partidos, tornando a una posición apolítica como en los setentas antes de las selecciones del 1988.

Desde la construcción del segundo piso (2002-2006) hasta la fecha, los megaproyectos públicos y privados se han confrontado con nuevas expresiones de malestar y movilizaciones de vecinos, que en hechos comprobaron esta escisión de la política en la ciudad, las dos vías para ejercer ciudadanías donde en su caso les toca la brecha arisca: muy escasa atención de partidos y funcionarios, muy poco presencia como un asunto de la agenda pública de la ciudad y escasas negociaciones (Álvarez, 2016: 41).

La socióloga María Cristina Sánchez, menciona que las luchas urbanas se caracterizan por tres actores, las organizaciones sociales, las vecinales, y las civiles, estas han incidido en las política públicas y han orientado la problemática de los problemas de la vivienda, esta participación ciudadana, varía dependiendo de diversos factores, de niveles, como la gestión pública y de esta manera la participación ciudadana se legitima como un espacio de ejercicio del poder en relación a los derechos y deberes.

...las atribuciones y funciones de los órganos de representación territorial (representantes de manzana, comités ciudadanos, consejos de los pueblos, y consejos delegacionales) son extremadamente limitadas para enfrentarla problemática y los nuevos procesos urbanos por lo que la tendencia mayoritaria ha sido la de confrontar y asociaciones uniones de colonos, organizaciones vecinales, la mayor parte registradas formalmente como asociaciones civiles con adscripción territorial, con objeto de tener una representación legal para incidir en la definición e implementación de la política urbanas (Álvarez, 2016: 206).

De acuerdo a Sergio Tamayo citado por Sánchez, ciudadanía se compone de tres dimensiones, la primera es la que constituye la relación entre el Estado y la sociedad civil, involucrando concepciones de nación y nacionalidad y expresiones jurídicas y culturales: la segunda tiene que 
ver con los derechos y obligaciones; la tercera ve la participación como el proceso político de formar parte de una comunidad (Álvarez, 2016: 207). Sánchez menciona, la relevancia que ha tenido el MUP en la solución del problema de la vivienda y el mejoramiento de la calidad de vida de los sectores populares, siendo la Ciudad testigo de estas luchas, y que estas luchas reaparecen de nuevo en otras formas de lucha, como ya lo hemos mencionado, en este sentido, como menciona Patricia Safa citada por Sánchez,

La gente se vincula los vecindarios gracias a los procesos simbólicos pero también afectivos, que es lo que permite la construcción de lazos y sentimientos de pertenencia con ese lugar. Las personas reconocen un lugar, un vecindario en la medida en la que pueden elaborar significados como referentes como referentes importantes de adscripción. Sin embargo el contenido que los sujetos y los grupos conceden a estas identidades vecinales son muy diversos, y por lo mismo son el resultado de negociaciones, de acuerdos y desacuerdos, de desgarres y conflictos entre y al interior de los distintos grupos (...) En este sentido, la revitalización de las identidades vecinales responde no solo a una añoranza por el pasado, sino también a nuevas situaciones problemáticas en el presente y/o proyectos de utopías futuras (Safa,1998:18) (Álvarez, 2016: 207).

En plena transición y adaptación a los nuevos escenarios, ya planteados, que se configuran en la Ciudad de México, la influencia del MUP se sigue vislumbrando este tipo de relaciones en las colonias, desde un recuerdo que parte de los primeros procesos de urbanización con una dirigencia urbano popular, y que sigue emergiendo en momentos de gran necesidad, desde la experiencia que les ha dejado éste movimiento. No obstante a que los conflictos están presentes entre facciones y grupos, siguen emergiendo y apagándose movimientos constantemente en las colonias. El MUP ha resurgido y si bien retoma algunas demandas de la década de 1970, ha incluido nuevas.

Así en el afán de por restaurarse y cobrar fuerza, en octubre del año 2000 con la realización de la Primera Asamblea Mundial de Pobladores en la ciudad de México, bajo el lema "Repensar la ciudad desde la gente", las organizaciones urbanas del país empezaron a perfilar e impulsar la lucha por la defensa de los derechos humanos y una primera visión sobre el derecho a la ciudad (...) En encuentro Nacional del Movimiento Urbano Popular (2005) las organizaciones presentes resolvieron reivindicar y hacer suyo el Pacto Internacional de los Derechos Económicos, Sociales y Culturales (PIDESC) de Naciones Unidas, los acuerdos internacionales en materia ambiental, así como el derecho a la ciudad, por lo que acordaron difundir la Carta Mundial por el Derecho a la Ciudad (...) ...finalmente la carta es suscrita por el jefe de gobierno, representantes de organismos sociales y civiles, la presidenta de la Comisión de Gobierno de la Asamblea Legislativa del Distrito Federal, el presidente del Tribunal Superior de Justicia del Distrito Federal y el presidente de la Comisión de Derechos Humanos del Distrito Federal, en 2010 (Álvarez, 2016: 211-212).

Los objetos del plan de derecho a la ciudad, son la construcción de una ciudad incluyente, justa e impulsar procesos de organización social; el fortalecimiento del tejido social y la construcción de ciudadanía; la construcción de una economía urbana equitativa. En donde los principios rectores del derecho a la ciudad son la libre determinación; no discriminación; igualdad; equidad de género; equidad social; atención prioritaria a personas y colectivos en situación de discriminación; solidaridad y cooperación entre los pueblos; participación; transparencia y 
rendición de cuentas; corresponsabilidad; justicia distributiva, (Álvarez, 2016: 220).

Finalmente la codicia vita en la inversión en la ciudad, no se han detenido y como ejemplo se recuerda la elaboración del Programa General de Desarrollo Urbano 2012 en donde se fortalecieron lo instrumentos de planeación delegacional y las normas de reordenación y desarrollo urbano en las Zonas Especiales de Desarrollo Económico y Social (Zodes), que trajo consigo movilizaciones de vecinos y de la sociedad en contra de estas ya que se convalidaban una serie de prácticas que solo beneficiaban a al gobierno de la ciudad y las empresas privadas.

Algunos movimientos se han apagado, como las anteriores descritas, pero siguen emergiendo nuevos con sus características propias. No obstante, se ha podido apreciar es estos movimientos la influencia del MUP y la experiencia de sus líderes y militantes en su participación en los MOSU.

De este modo, se puede apreciar que el Estado no tiene incidencia en la capacidad que tienen las personas líderes y militantes para configurar vínculos de afecto y solidaridad, alimentados muchos de ellos por prácticas y costumbres culturales fortalecidos por instituciones sociales. 
Bibliografía

Álvarez Enríquez, Lucía, Introducción. Ciudad y Ciudadanía, en Álvarez Enríquez Lucía (coord.), Ciudadanía y nuevos actores en grandes ciudades, México, Juan Pablos, 2016.

Carlos Pereyra, Antonio Gramsci, Estado y Sociedad Civil, en Cuadernos políticos, número 54/55, México, D.F., editorial Era, mayo-diciembre de 1988.

Haber Paul, La migración del Movimiento Urbano Popular a la política de partido en el México contemporáneo, en Revista Mexicana de sociología, Vol. 7(2), México, D.F., 1 abril 2008, pp.213-245.

Icazuriaga Montes, Carmen, La metropolización de la ciudad de México a través de la instalación industria, México, La Casa Chata, 1992.

Iturbide Espinoza Bulmaro, Movimiento por la paz con justicia y dignidad. Estados emocionales, ceremonias y rituales de rebelión, México, Tesis de licenciatura, 2013.

John Gledhill, De la macroestructura al microproceso: análisis antropológico de las prácticas políticas, El poder y sus disfraces, Barcelona, Bellaterra, 2000.

Kate Crehan, Gramsci Hoy, en Gramsci, Cultura y antropología, Bellaterra, 2002.

Lomnitz Larissa A., Cómo sobreviven los marginados, México, Siglo XXI, 1975.

Marcel Mauss, Sociología y antropología, Madrid, Tecnos, 1979.

Melucci Alberto, Acción colectiva, vida cotidiana y democracia, México, El Colegio de México, 1999.

Nicholas Ralph. Rules, resources and political activity, en: Swartz, M. Local level politics, social and cultural perspectives, Londres, University of London Press LTD, 1969.

Nuñez González Óscar, Innovaciones democrático culturales del movimiento urbano popular, México, UAM, 1990.

Ramírez Sáiz Juan Manuel, Organizaciones populares y lucha política, en Cuadernos Políticos, número 45, México D.F., ed. Era, enero-marzo, pp.38-55. 1986.

San Juan Victoria, Carlos, Pensar en Tiempo de secas. Ciudadanías y Democracias Liberales, en 
Álvarez Enríquez, Lucía (coord.), Ciudadanía y nuevos actores en grandes ciudades, México, Juan Pablos, 2016.

Sánchez-Mejorada F., María Caristina, Por el derecho a la ciudada. Movimientos y luchas urbanas en la ciudad de México, en Álvarez Enríquez, Lucía (coord.), Ciudadanía y nuevos actores en grandes ciudades, México, Juan Pablos, 2016.

Tamayo Sergio, Del movimiento urbano popular al movimiento ciudadano, en Estudios Sociológicos, Vol. 17(50), México D.F., pp. 499-518, 1 mayo 1999.

Turner Victor W., El proceso ritual, Madrid, Taurus, 1988. 


\section{Ala}

Casa abierta al tiempo

UNIVERSIDAD AUTÓNOMA METROPOLITANA-IZTAPALAPA

DIVISIÓN DE CIENCIAS SOCIALES Y HUMANIDADES

POSGRADO EN CIENCIAS ANTROPOLÓGICAS

CONSTANCIA DE EVALUACIÓN DEL ENSAYO

PARA LA OBTENCIÓN DEL DIPLOMA EN LA

ESPECIALIZACIÓN EN ANTROPOLOGÍA POLITICA

\begin{tabular}{|c|c|c|}
\hline DLA & MES & AÑO \\
31 & 10 & 2019 \\
\hline
\end{tabular}

ALUMNA: GONZÁLEZ GONZÁLEZ KITZIA MAYELA

MATRICULA: 2183800046

TRIMESTRE 19-P

DIRECTOR: DR. HÉCTOR TEJERA GAONA

LA ALUMNA PRESENTÓ EL ENSAYO TITULADO:

La influencia del Movimiento Urbano Popular a los Movimientos Sociales Urbanos en la Ciudad de México: Un análisis de los liderazgos y los militantes de esta transición.

OBTENIENDO LA CALIFICACIÓN DE:

APROBAR $($ )

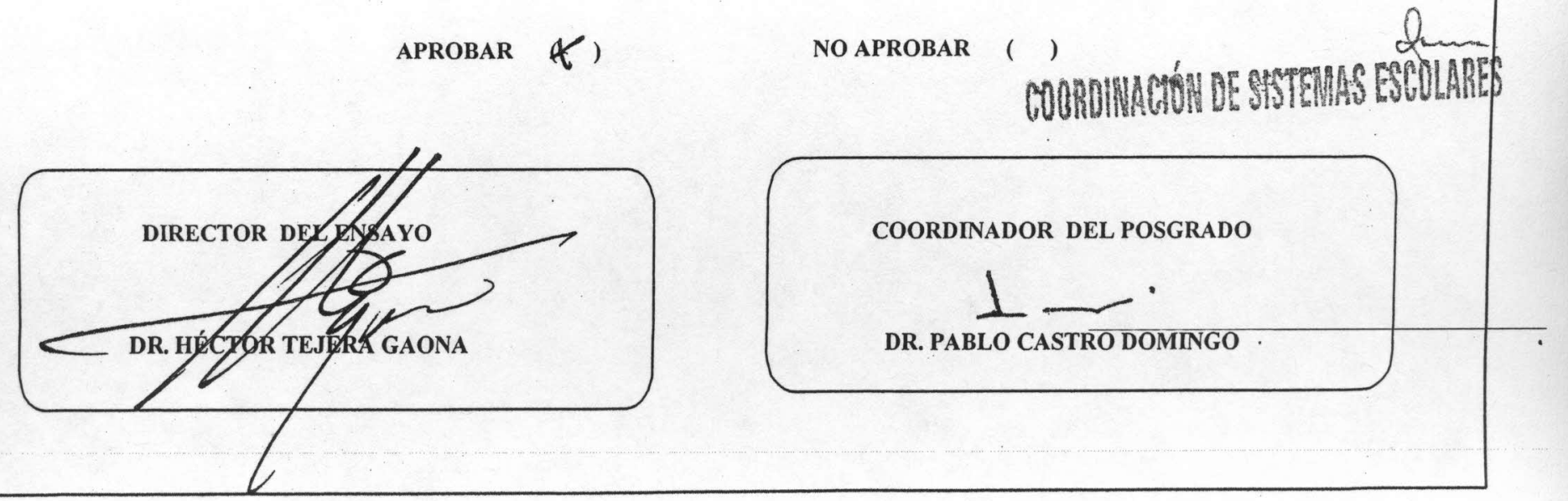

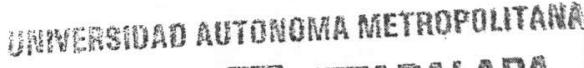

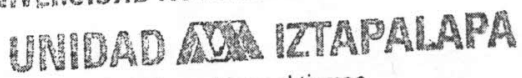

Casa abierta al tiempo

04 NOV LUTY 


\section{Aal}

Casa abierta al tiempo

UNIVERSIDAD AUTONOMA METROPOLITANA

Fecha: 04/03/2020

\section{Representante Legal}

\section{Universidad Autónoma Metropolitana}

Presente

Kitzia Mayela González González alumno(a) del programa de posgrado en Ciencias Antropológicas, con número de matrícula 2183800046, manifiesto bajo protesta de decir verdad ser el autor (es) intelectual de la presente tesis de grado (obra) titulada La influencia del Movimiento Urbano Popular a los Movimientos Sociales Urbanos en la Ciudad de México: Un análisis de los liderazgos y los militantes de esta transición, y que esta es una obra original, la cual no tiene contenido lascivo contra terceros, por lo que de conformidad con los artículos 26 y 27 de la Ley Federal del Derecho de Autor, autorizo a la Universidad Autónoma Metropolitana para que por tiempo indeterminado y de manera gratuita, haga uso de mi obra para consulta, descarga total o parcial, difusión, reproducción en cualquier medio físico o electrónico, adecuación de formato con fines académicos, de investigación y sin fines de lucro, siempre y cuando la Universidad Autónoma Metropolitana respete los derechos morales que ostento como autor, conforme a los artículos 18 y 21 de la citada Ley.

Asimismo, me hago consciente y sabedor de que a través del acceso abierto en el repositorio de la Universidad Autónoma Metropolitana, mi obra estará considerada como divulgación previa con todas las implicaciones que se derivan de ello.

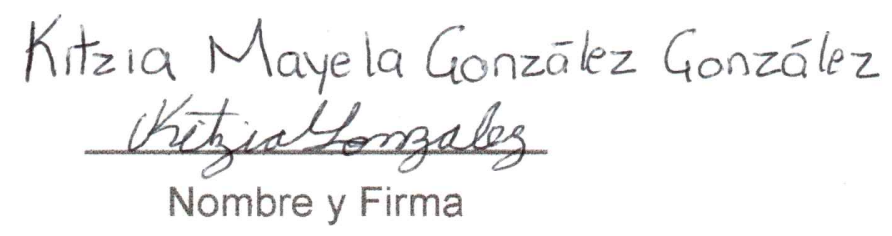

